\title{
A comparison of the responses of two tropical specialist herbivores to host plant patch size
}

\author{
Catherine E. Bach \\ Division of Biological Sciences, University of Michigan, Ann Arbor, MI 48109, USA
}

\begin{abstract}
Summary. The effects of host plant patch size on the abundances of two specialist herbivores (the chrysomelid beetle, Acalymma innubum and the pentatomid bug, Piezosternum subulatum) were investigated in a natural forest community in the Virgin Islands. Abundances were compared early and late in the season in different sized patches of the cucurbit host plant (Cayaponia americana) growing in open habitat (with no surrounding plant community) and forest habitat (with diverse surrounding plant community). For both herbivore species, adult abundances per patch were positively correlated with patch leaf area, but there was a significant patch size effect (i.e., correlation between herbivore density per unit plant and patch leaf area) only for beetles in the forest habitat. Both herbivore species were significantly affected by surrounding plant diversity, but in opposite ways: beetles were more abundant in open patches whereas bugs were more abundant in forest patches. Relationships between abundance and patch size in open and forest patches changed through the season for both herbivore species. These changing abundance patterns are discussed with respect to (1) increases in the diversity of the plant community surrounding host plant patches, and (2) differences in herbivore movement patterns.
\end{abstract}

The influence of plant spatial pattern - plant density, plant diversity and host plant patch size - on the population ecology of specialist insect herbivores has been investigated for a variety of insect-plant systems (e.g., Root 1973; Ralph 1977; Bach 1980 b; MacGarvin 1982). While dramatic effects are usual, no general patterns regarding the effects of plant spatial pattern on herbivorous insects have yet emerged, despite two recent reviews on the subject (Kareiva 1983; Stanton 1983). For example, different studies have found either greater herbivore densities in large patches (Thompson 1978; Kareiva 1983), in small patches (Cromartie 1975; Maguire 1983), or no significant patch size effect (Raupp and Denno 1979; MacGarvin 1982).

Part of the reason for this lack of general patterns is that most studies confound several plant spatial pattern variables. Thus, the consequences of a single aspect of plant spatial pattern often can not be demonstrated because other aspects of plant spatial pattern covary with the one of interest. For example, in most natural systems, patch size is inversely related to plant diversity. As patch size of a particular plant species increases, there is a corresponding in- crease in the proportion of conspecific plants (=host plants in the case of specialist herbivores) to heterospecific plants (=nonhosts), and thus a decrease in the diversity of the plant community surrounding individual host plants. Few studies have separated the effects of the confounded variables of patch size and plant diversity.

Here I report on a study in which I controlled for confounded changes in plant diversity while examining the effects of host plant patch size on herbivore population dynamics in a natural community. The purpose of this study was to compare the response of 2 specialist herbivore species to host plant patches that differed in size and surrounding plant diversity. Two questions were investigated: (1) What is the effect of host plant patch size and surrounding plant diversity on the abundances of the 2 herbivore species?, and (2) How do changes in host plant patches through the season influence herbivore population densities?

\section{Methods}

This study was carried out in a tropical moist forest on St. Peter's Mountain ( $460 \mathrm{~m}$ elevation) on St. Thomas, U.S. Virgin Islands $\left(18^{\circ} 20^{\prime} \mathrm{N}, 65^{\circ} \mathrm{W}\right)$ between January and March 1980. The host plant studied was a vine, Cayaponia americana (Family Cucurbitaceae), an early colonizer of recently disturbed areas. This plant grew in distinct patches along both sides of a road that had been cut through the forest 3 months prior to the start of the study. As a result of the steep topography, the host plant grew in 2 different microhabitats at the same site. Along the upper side of the road, the host plant was a climber on shrubs and trees at the forest edge (henceforth called "forest" habitat). In contrast, on the other side of the road, $C$. americana typically occurred on the ground in nearly monospecific stands, in a sunny location removed from the forest ("open" habitat).

The diversity of the plant community surrounding host plant patches differed greatly between open and forest habitats. In forest patches (as compared to open patches), a significantly greater proportion of host plants grew up trees and shrubs (Bach 1984), both of which indicate a high surrounding plant diversity. In open patches, vegetation surrounding patches was usually entirely absent. Thus, these two microhabitats at the same site provide a control for the confounded changes in plant diversity which usually accompany changes in patch size in natural communities. 
By comparing the same sized patches in open habitat and forest habitat, it was possible to separate the effects of changes in surrounding plant diversity associated with changes in patch size from the effects of patch size per se.

Patches were defined as areas of continuous cover by C. americana bounded by a minimum of $0.5 \mathrm{~m}$ (parallel to road) without any $C$. americana. Leaf area was used as the measure of patch size, since (1) leaf area best estimates the amount of plant resource available to herbivores, and (2) leaf area was highly significantly correlated $(r=0.90$ for open patches, $\mathrm{r}=0.89$ for forest patches; $p<0.01$ for both) with the geographic area of patches (Bach 1984). Thus, patch leaf area will henceforth be refered to as patch size.

Patch size and surrounding plant diversity were measured on 4 February and again on 12 March. Leaf area was estimated as the area that would be filled with one solid layer of leaves. Leaf areas were estimated to the nearest $1 / 8 \mathrm{~m}^{2}$ for patches with less than $1 \mathrm{~m}^{2}$ leaf area and to the nearest $1 / 2 \mathrm{~m}^{2}$ for patches with greater than $1 \mathrm{~m}^{2}$ leaf area, using a $1 \mathrm{~m}^{2}$ sampling frame. To determine the diversity of the surrounding vegetation, the percentage of host plant growing in each of the following 4 conditions was estimated to the nearest $5 \%$ for each patch: (1) on bare ground, (2) on ground touching foliage of other plant species, (3) on shrubs, and (4) on trees. Further details of methods are described in Bach (1984).

The two most common herbivore species found were Acalymma innubum (Fab.) (Coleoptera: Chrysomelidae) and Piezosternum subulatum (Thunberg) (Hemiptera: Pentatomidae). Both of these species are specialists on plants in the family Cucurbitaceae. Adults of $A$. innubum feed on cucurbit leaves and flowers, while the larvae are root feeders (Munroe and Smith 1980). In contrast, both adults and nymphs of $P$. subulatum are found on host plant leaves and stems. They most probably feed on plant sap, since a closely related cucurbit specialist from Africa $(P$. calidum) was shown to be a sap-sucking herbivore (Goodchild 1967).

Abundances of these herbivore species were assessed on 6 days between 26 January and 18 March (26 January, 2, 9 and 19 February, 2 and $18 \mathrm{March}$ ). A direct observation method was utilized as neither species was disturbed by sampling (Goodchild 1967; Bach 1984). All censuses were conducted between 0900 and $1200 \mathrm{~h}$ and the order of censusing patches was randomized. Data on adult and nymph abundances were recorded separately for pentatomid bugs.

Because of changes in the size of host plant patches and the number of host plant patches between the February and March measurements of patch size, data were analyzed separately for two time periods (early in the season, 26 Jan$19 \mathrm{Feb}$; and late in the season, 2-18 March). Comparisons of patch sizes and herbivore densities were carried out using Mann-Whitney U tests, since the data violated the normalcy assumption for parametric statistics. To determine the effect of surrounding plant diversity on herbivore abundances, relationships between numbers of herbivores per patch and patch size were compared between the open and forest habitat using regression and covariance analysis. Abundance and patch size variables were log transformed because of the extreme variability. To determine the effect of patch size on herbivore abundances, relationships between herbivore density per plant (in this case, per $\mathrm{m}^{2}$ leaf area) and patch size were analyzed using product-moment correla- tion. This effect of patch size on herbivore density per unit plant will be henceforth referred to as a patch size effect.

\section{Results}

Over the entire season, individuals of Acalymma innubum (beetles) comprised $68.5 \%$ of the total adult herbivore fauna censused (Table 1), but only $15.7 \%$ of the total herbivore fauna [taking into account nymphs of Piezosternum subulatum (bugs)]. The 2 herbivore species had very different overall abundances in open versus forest patches. Open patches supported $64.6 \%$ of all beetles, but only $12.4 \%$ of all bugs found. Beetle densities (per $\mathrm{m}^{2}$ leaf area) were significantly greater in open than in forest patches early in the season, but not late in the season (Table 2). Bug densities, both adult and nymph, were greater in forest than in open patches, but these differences were significant only for adults late in the season (Table 2). Because the effects of habitat (open vs. forest) on herbivore densities differed for the two species and differed through the season, results will be discussed separately for early versus late in the sea-

Table 1. Total numbers of herbivores censused in open and forest patches on all sampling dates

\begin{tabular}{lll}
\hline & Open patches & Forest patches \\
\hline $\begin{array}{l}\text { Acalymma innubum } \\
\text { (beetles) }\end{array}$ & 943 & 516 \\
$\begin{array}{l}\text { Piezosternum subulatum adults } \\
\text { (bugs) }\end{array}$ & 105 & 565 \\
\begin{tabular}{l} 
P. subulatum nymphs \\
\hline
\end{tabular} & 765 & 6421 \\
\hline
\end{tabular}

Table 2. Patch leaf areas and herbivore densities for open patches and forest patches, both early in the season and late in the season. Herbivore densities are the total number of herbivores per $\mathrm{m}^{2}$ leaf area over the first four sampling dates (for early in the season) and over the last two sampling dates (for late in the season). Medians are presented, with 25 th and 75 th percentiles in parentheses. Sample sizes are: open, $N=32$ (early), $N=23$ (late); forest, $N=18$ (early), $N=8$ (late)

\begin{tabular}{|c|c|c|c|c|}
\hline & Open patches & Forest patches & $\begin{array}{l}\text { Mann- } \\
\text { Whitney U } \\
\text { Statistic }\end{array}$ & $P$ \\
\hline \multicolumn{5}{|c|}{ Beetle density } \\
\hline Early $^{\mathrm{a}}$ & $7.2(0,10.6)$ & $0 \quad(0,2.1)$ & 144 & $* *$ \\
\hline Late & $3.8(0,7.5)$ & $1.2(0,4.3)$ & 74 & NS \\
\hline \multicolumn{5}{|c|}{ Adult bug density } \\
\hline Early & $0.3(0,8.0)$ & $1.7(0,20.2)$ & 223 & NS \\
\hline Late & $0 \quad(0,0.4)$ & $2.7(0,5.2)$ & 35 & $* *$ \\
\hline \multicolumn{5}{|c|}{ Bug nymph density } \\
\hline Early & $13.3(0,60.0)$ & $30.0(0,140.0)$ & 261 & NS \\
\hline Late & $0 \quad(0,0)$ & $0 \quad(0,56.5)$ & 65 & NS \\
\hline \multicolumn{5}{|c|}{ Patch leaf area } \\
\hline Early $^{\mathrm{a}}$ & $0.3(0.1,1.0)$ & $0.2(0.1,3.5)$ & 286 & NS \\
\hline Late & $0.7(0.3,4.0)$ & $1.0(0.1,4.0)$ & 84 & NS \\
\hline
\end{tabular}

$\mathrm{NS}=P>0.05 ; * * P<0.01$

a From Bach (1984) 
son. I will first discuss changes in host patches through the season, and secondly, relationships between herbivore abundance and host plant patch size for (1) beetles and (2) bugs.

\section{Host plant patches}

Although host plant patches did not differ in size between the open and forest habitat either early or late in the season (Table 2), both leaf area and the diversity of the surrounding vegetation were constantly changing for each patch through the season. Between the first sampling date (early in the season) and the second sampling date (late in the season), the number of patches significantly decreased due to plant death (open, $N=9$; forest, $N=10$ ). However, other patches increased in size because of plant growth (see Table 2). In addition to changes in the sizes and numbers of patches, the diversity of the vegetation surrounding patches increased over the season. Early in the season, open patches were composed primarily of Cayaponia americana. In fact, the median percentage of host plant growing on bare ground in open patches was $90 \%$. Five weeks later (during the second sampling period), many other plant species had appeared, increasing the diversity of the surrounding community, and the median percentage of host plant growing on bare ground had decreased to $46 \%$. Along with this decrease was a concommitant increase in the percentage of host plant growing on the ground touching vegetation of other plant species. In contrast to open patches, forest patches consistently had low percentages of host plant growing on bare ground, from $11 \%$ early in the season to $2 \%$ late in the season.

\section{Beetle-host plant patch dynamics}

To examine the effect of surrounding plant diversity on herbivore abundances, we need to compare abundances in open versus forest patches of equal sizes (i.e., compare relationships between herbivore abundance per patch and patch size). Early in the season, beetle abundance was positively related to patch size in both habitats (Fig. 1a; Bach 1984). For a given patch size, open patches had significantly more beetles than did forest patches (Bach 1984; Covariance analysis: equality of regressions, $\mathrm{F}=5.38, P=0.008$ ). In open patches, numbers of beetles were directly proportional to patch size for the entire range of patch sizes. However, clearly a linear model is not adequate for the relationship in forest patches, where there appears to be a critical patch size below which patches do not have any beetles at all. Thus, there appears to be a stronger effect of habitat (open vs. forest) on beetle numbers in small patches. Late in the season, beetle numbers were still correlated with patch leaf area both in the open and the forest (Fig. 1b), but these regression lines are no longer significantly different (Covariance analysis: equality of regressions, $\mathrm{F}=1.36, P=0.27$ ).

To examine the effect of host plant patch size on herbivore abundance, we need to look at how patch size influences herbivore density per plant (or in this study, per $\mathrm{m}^{2}$ host plant leaf area). Early in the season, beetle densities were significantly correlated with patch size in the forest only (Table 3), indicating that only in the forest was there a disproportionate concentration of beetles in larger patches (a patch size effect). Late in the season, relationships between beetle density and patch size were not significant in either open or forest patches (Table 3).
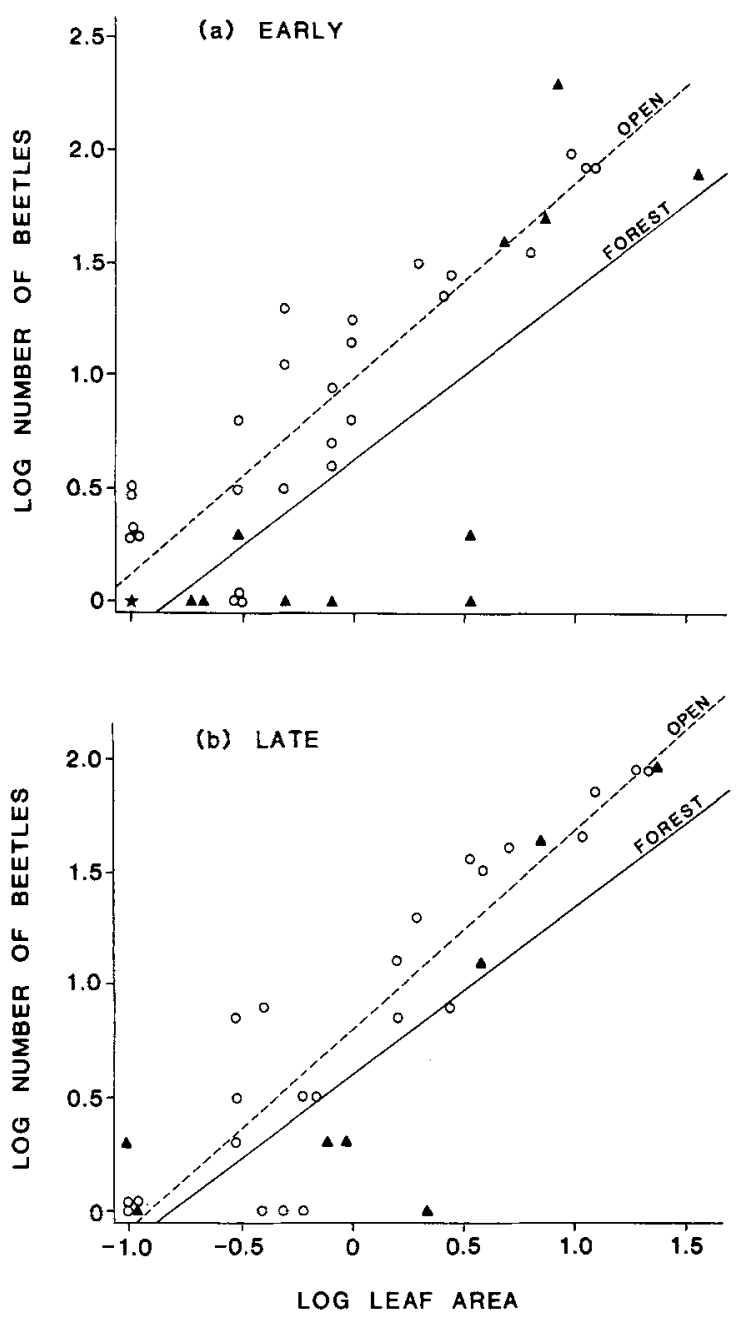

Fig. 1a, b. Relationship between total number of individuals of Acalymma innubum (beetles) per patch and patch leaf area $\left(\mathrm{m}^{2}\right)$ in the open (0) and forest (A). Both variables were log transformed: beetles, $\log (x+1)$; leaf area, $\log x$. a Early in season. Number of beetles represents the total number over the four sampling dates. Equations for regression lines: open (---), $y=0.88 x+0.99, r=$ $0.91, P<0.01$; forest $(-), y=0.77 x+0.63, r=0.82, P<0.01$. $*=6$ data points for open patches and 7 data points for forest patches. b Late in season. Total number of beetles over the last two sampling dates. Equations for regression lines: open (--), $y=0.89 x+0.80, r=0.92, P<0.01$; forest $(-), y=0.75 x+0.61$, $r=0.81, P<0.05$

\section{Bug-host plant patch dynamics}

Relationships between number of herbivores per patch and patch size were very different for bugs than for beetles. Early in the season, numbers of adults were significantly correlated with patch size only in the forest (Fig. 2a). Similarly, numbers of nymphs increased with patch size in the forest $(r=0.52, N=18, P<0.05)$. Nymph abundances were negatively correlated with patch size in the open $(r=-0.44$, $N=32, P<0.05$ ), but only because all of the 6 largest patches had no nymphs. Thus, in contrast to the effect of habitat in determining beetle numbers only in small patches, there was a habitat effect in determining numbers of bugs only in large patches.

Late in the season, numbers of adults were significantly related to patch size both in the open and the forest (Fig. 2b). Furthermore, for a given size patch, there were 
Table 3. Correlations (product-moment) between patch size (log leaf area) and herbivore density (number of herbivores per $\mathrm{m}^{2}$ leaf area) in open and forest patches, both early in the season ( $N=32$, open; $N=18$, forest) and late in the season $(N=23$, open; $N=8$, forest)

\begin{tabular}{lll}
\hline & Open patches & Forest patches \\
\hline Beetles & & \\
Early & $r=0.12$ & $r=0.54^{*}$ \\
Late & $r=0.14$ & $r=-0.02$ \\
Adult bugs & & \\
Early & $r=-0.20$ & $r=-0.28$ \\
Late & $r=0.16$ & $r=-0.14$ \\
Bug nymphs & & \\
Early & $r=-0.49^{* *}$ & $r=-0.11$ \\
Late & $r=0.36$ & $r=0.70^{*}$ \\
\hline
\end{tabular}

* $P<0.05 ; * * P<0.01$
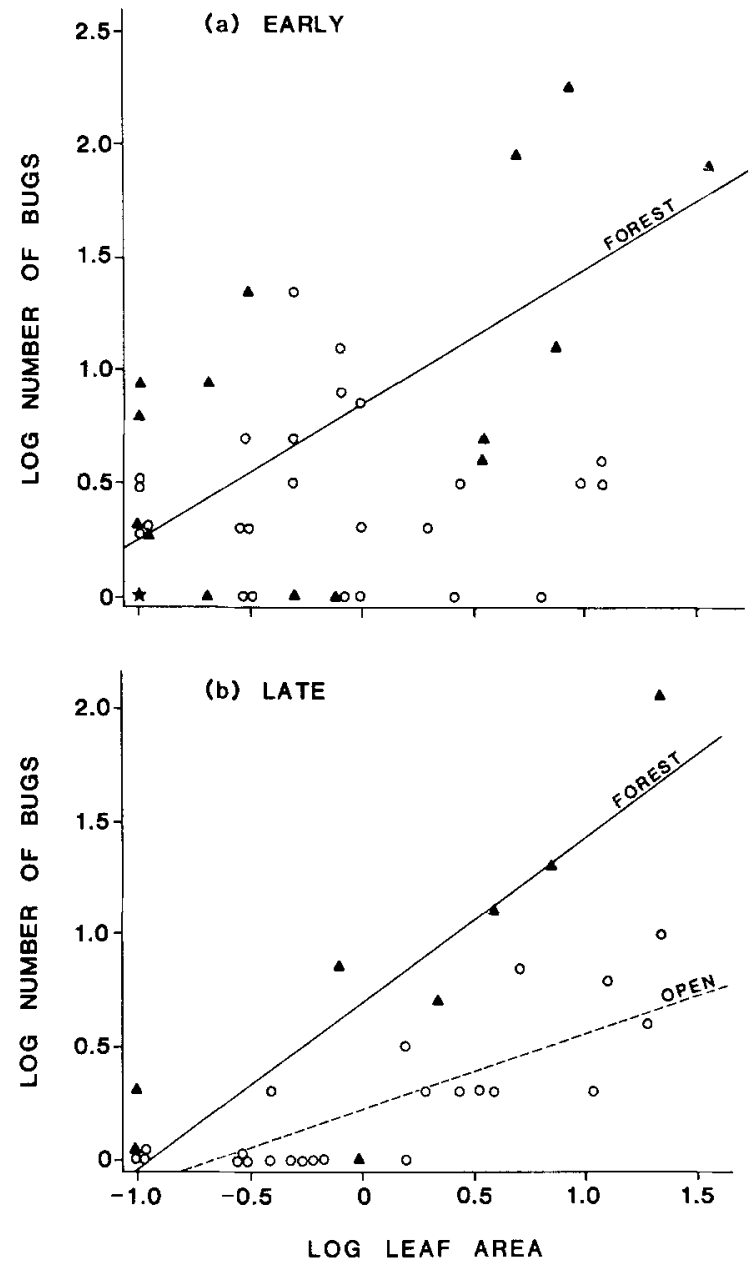

Fig. 2a, b. Relationship between total number of adults of Piezosternum subulatum (bugs) per patch and patch leaf area $\left(\mathrm{m}^{2}\right)$ in the open (0) and forest $(\Lambda)$. Variable transformations as in Fig. 1. a Early in season. There was no significant relationship in the open habitat $(r=0.27, N=32, P>0.05)$. Equation for regression line in the forest: $y=0.60 x+0.87, r=0.69, P<0.01$. $*=7$ data points for open patches and 3 data points for forest patches. $b$ Late in season. Equations for regression lines: open (-), $y=0.35$ $x+0.22, r=0.82, P<0.01$; forest $(\longrightarrow), y=0.73 x+0.69, r=0.87$, $P<0.01$ significantly more adults in the forest than the open (Covariance analysis: equality of regressions, $\mathrm{F}=18.1, P=$ 0.0000 ). Abundances of nymphs were positively related to patch size in the open $(r=0.44, N=23, P<0.05)$, but there was no significant relationship in the forest $(r=0.69, N=8$, $P>0.05$ ).

There was no patch size effect for adults in either habitat in either part of the season (Table 3), since densities were never significantly correlated with patch size. Early in the season, nymph densities were negatively correlated with patch size in the open (Table 3), a consequence of the absence of nymphs in large patches. Late in the season, nymph densities were positively related to patch size in the forest (Table 3).

\section{Discussion}

It is not surprising to find that the number of herbivores in a patch is consistently proportional to the amount of host plant resource available in that patch. However, it is interesting that the relationships between herbivore abundance and patch size differ in 2 habitats at the same site, for 2 herbivore species at any point in time, and for the same herbivore species over time. Other studies have also reported a difference in herbivore response to the same set of host plant patches (Cromartie 1975; Raupp and Denno 1979; Kareiva 1981; MacGarvin 1982; Maguire 1983).

The comparison of herbivore abundances in low diversity open patches and in higher diversity forest patches of similar sizes allows one to separate the effects of changes in surrounding plant diversity associated with increasing patch size from the effects of patch size per se. Results from this study strongly indicate the importance of changes in surrounding plant diversity, since both herbivore species displayed significantly different patterns of abundance in open versus forest patches of the same size. Similarly, Kareiva (1983) reports differences in herbivore abundances in the same sized patches with goldenrod versus cultivated background vegetation.

Moreover, there was a very different effect of patch size on herbivore density (per unit leaf area) in the open versus the forest, at least for beetle herbivores. Beetle densities were not affected by patch size in the open patches (which had very little or no surrounding plant diversity), but were affected by patch size in the forest patches (which had surrounding plant diversity). Thus, surrounding plant diversity seems to be clearly associated with the patch size effect. Similar responses to surrounding native vegetation by specialized herbivorous insects have been reported in other studies (Root 1973; Smith and Whittaker 1980; Rausher 1981).

One might have predicted that both herbivore species should respond similarly to plant diversity. However, only beetles showed the expected decreased density in more diverse habitats, as found for the majority of specialist herbivores (Risch et al. 1983). These results on Acalymma innubum are consistent with the decreased population densities of a closely related species, Acalymma vittatum, in diverse agricultural plots compared to monocultures (Bach 1980a, 1980 b).

The different patterns of abundance in the open versus the forest for the 2 herbivore species may result from differences in herbivore movement behavior. Observations of 
beetle behavior showed that they fly when disturbed, landing randomly on host and nonhost plants (Bach 1984). However, beetles remain on host plants for significantly longer periods of time than on nonhost plants (Bach 1984). Thus, beetle numbers may be greater in the open than in the forest because a given size patch and its surrounding habitat have a greater proportion of host plants because of the absence of surrounding nonhost vegetation. As a result, beetles would tend to stay in the open habitat for longer periods of time. Beetle numbers may differ more between the open and the forest in small patches relative to large patches because small open and forest patches differ more dramatically in the proportion of hosts relative to nonhosts in the surrounding plant community. Consistent with this is the observation that there are significant differences in tenure time for beetles in small patches in the open compared to the forest, but no difference in tenure times in large open vs. forest patches (Bach 1984).

Movement patterns of bugs were in direct contrast to those of beetles. Pentatomid bugs remain stationary even when disturbed and are rarely, if ever, found on nonhost plants. Thus, the presence of surrounding nonhost plants in the forest habitat did not have a negative influence on bug numbers, as it did on beetle numbers. The greater numbers of adult bugs in the forest versus the open may have resulted from a preference for shaded habitats or changes in plant quality when host plants were growing in a more shaded habitat. Feeding choice experiments with leaves from open vs. forest plants were not conducted with pentatomid herbivores, but beetles did distinguish between open vs. forest leaves in feeding tests (Bach 1984).

The changes through the season in the relationships between herbivore abundance and patch size most probably result from the increase over time in the diversity of surrounding vegetation. As the frequency of non-host plants surrounding open patches increased through the season, the difference between open and forest patches decreased, both in terms of surrounding plant diversity and light level. Nonhost plants directly influence beetle movements (Bach 1984), but also indirectly influence beetles via shading, since beetles prefer sunny habitats and foliage growing in the sun (Bach 1984). Thus, the development of the surrounding plant community in open patches seems to be responsible for the lack of a difference in the beetle abundance-patch size relationships late in the season.

This study points out some of the difficulties involved in trying to make generalizations about the response of specialist herbivores to differences in plant spatial dispersion. Even for only 2 herbivore species specializing on the same host plant, there were differences in responses both to patch size and plant diversity. Moreover, the interaction between the herbivores and their host plant patches changed as patch structure and diversity changed. Results from this study emphasize the role of the plant comunity surrounding host plant patches in influencing population dynamics of herbivores within host plant patches. The strong interaction found in this study between patch size and surrounding plant diversity points out how essential it is to control for confounded interrelated variables in studies of effects of plant dispersion on herbivores.

Acknowledgements. This research was sponsored by a Chaim Weizmann Postdoctoral Fellowship from the California Institute of Technology. Logistical support was provided by the College of the Virgin Islands. I thank D. Johnson for identifying the host plant, R. White, Systematic Entomology Laboratory, United States Department of Agriculture, for identifying Acalymma innubum (Fab.), and T.J. Henry, SEL, USDA, for identifying Piezosternum subulatum (Thunberg). J. Bronstein and B. Hazlett provided helpful comments on the manuscript. Support during preparation of this paper was provided by NSF grant \# BSR-8315619.

\section{References}

Bach CE (1980a) Effects of plant diversity and time of colonization on an herbivore-plant interaction. Oecologia (Berlin) $44: 319-326$

Bach CE (1980b) Effects of plant density and diversity on the population dynamics of a specialist herbivore, the striped cucumber beetle, Acalymma vittata (Fab.). Ecology 61:1515-1530

Bach CE (1984) Plant spatial pattern and herbivore population dynamics: plant factors affecting the movement patterns of a tropical cucurbit specialist (Acalymma innubum). Ecology 65:175-190

Cromartie WJ (1975) The effect of stand size and vegetational background on the colonization of cruciferous plants by herbivorous insects. J Appl Ecol 12:517-533

Goodchild AJP (1967) Shield bug (Piezosternum calidum Fab.) infestation of oyster nut. Afr Ag For J 33:192-196

Kareiva P (1981) Non-migratory movement and the distribution of herbivorous insects: experiments with plant spacing and the application of diffusion models to mark-recapture data. Ph.D. Dissertation. Cornell University, Ithaca, New York

Kareiva P (1983) Influence of vegetation texture on herbivore populations: resource concentration and herbivore movement. In: Denno RF, McClure MS (eds) Variable plants and herbivores in natural and managed systems. Academic Press, New York, pp 259-289

MacGarvin M (1982) Species-area relationships of insects on host plants: herbivores on rosebay willowherb. J Anim Ecol $51: 207-223$

Maguire LA (1983) Influence of collard patch size on population densities of Lepidopteran pests (Lepidoptera: Pieridae, Pluttellidae). Environ Entomol 12:1415-1419

Munroe DD, Smith RF (1980) A revision of the systematics of Acalymma sensu stricto Barber (Coleoptera: Chrysomelidae) from North America including Mexico. Mem Entomol Soc of Can 112

Ralph CP (1977) Effect of host plant density on populations of a specialized, seed-sucking bug, Oncopeltus fasciatus. Ecology 58:799-809

Raupp MJ, Denno RF (1979) The influence of patch size on a guild of sap-feeding insects that inhabit the salt marsh grass Spartina patens. Environ Entomol 8:412-417

Rausher M (1981) The effect of native vegetation on the susceptibility of Aristolochia reticulata (Aristolochiaceae) to herbivore attack. Ecology 62:1187-1195

Risch S, Altieri M, Andow D (1983) Agroecosystem diversity and pest control: data, tentative conclusions, and new research directions. Environ Entomol 12:625-629

Root RB (1973) Organization of a plant-arthropod association in simple and diverse habitats: the fauna of collards (Brassica oleracea). Ecol Monogr 43:95-124

Smith R, Whittaker J (1980) The influence of habitat type on the population dynamics of Gastrophysa viridula Degeer (Coleptera: Chrysomelidae). J Anim Ecol 49:225-236

Stanton ML (1983) Spatial patterns in the plant community and their effects upon insect search. In: Ahmad S (ed) Herbivorous insects: host-seeking behavior and mechanisms. Academic Press, New York, pp 125-157

Thompson J (1978) Within patch structure and dynamics in Pastinaca sativa and resource availability to a specialized herbivore. Ecology 59:443 448

Received May 30, 1985 